\title{
Isopropyl alcohol (70\%)-based hand sanitizer-induced contact dermatitis: A case report amid Covid-19
}

\author{
Deep Inder ${ }^{1}$, Pawan Kumar ${ }^{2}$ \\ From 'Professor and Head, Department of Pharmacology, Faculty of Dentistry, Jamia Millia Islamia, ${ }^{2}$ Additional Director, Directorate General of \\ Health Services, Government of NCT of Delhi, Karkardooma, New Delhi, India
}

\begin{abstract}
Indiscriminate use of alcohol-based hand sanitizers during the coronavirus-19 pandemic has led to adverse effects on the skin across the globe. We present the case of a 12-years-old child, who developed a skin rash on the dorsal aspect of the hands with overapplication of $70 \%$ isopropyl alcohol-based hand sanitizer. On examination, inflamed dark-colored skin with itching was noticed. Based on the history and examination, a diagnosis of "Isopropyl alcohol-based sanitizer-induced irritant contact dermatitis" was made. The application of offending sanitizer was immediately stopped. An improvement was seen 2 weeks after the application of topical corticosteroids and oral antihistamines. No re-challenge was subjected to the child. The Naranjo causality assessment score of six suggested probable association of adverse effect with the use of 70\% isopropyl alcohol. It can be concluded that alcohol-based hand sanitization to be reserved for outdoor use, whereas only soap and water should be promoted to be used at home for sanitizing hands. The risk of adverse reactions can be minimized by following the manufacturer's instructions and reducing the frequency of use of single hygiene products.
\end{abstract}

Key words: Coronavirus-19, Contact dermatitis, Hand sanitizer, Isopropyl alcohol

$\mathrm{C}$ hemical-based hand sanitizers-induced dermatitis is quite often seen among health care workers in various hospitals setting to the extent of $25-55 \%$. The most commonly used chemicals in hand hygiene products include chlorhexidine, 70\% isopropyl alcohol, cetrimide, sodium lauryl sulfate, triclosan, and sodium oleate. These hygiene products on frequent use can lead to irritant contact dermatitis, especially on the hands [1]. Irritant contact dermatitis has also been seen on the hands of sanitary and domestic helpers due to repeated use of soaps and detergents in various forms and in various concentrations for cleaning and washing utensils, clothes, floors, etc., at home [1,2].

There has been a dramatic increase in the use of alcohol-based hand sanitizers across the globe amid the coronavirus (Covid-19) pandemic. Studies have shown that alcohol (70\%)-based sanitizers are effective in preventing transmission of Covid-19 in various community settings [2]. Here, we report the case of a 12-yearold child, who developed a skin rash on the dorsal aspect of the hands with over-application of 70\% isopropyl alcohol-based hand sanitizer.

\section{Access this article online}

Received - 14 June 2020

Initial Review - 06 July 2020

Accepted - 14 July 2020

DOI: $10.32677 /$ IJCR.2020.v06.i07.017

\section{CASE REPORT}

A 12-year-old child of Indian origin, weighing $49 \mathrm{~kg}$, developed a skin rash on the dorsal aspect of the hands while staying at home amid complete lockdown in India. Parents telephonically revealed the history of frequent hand sanitization by the child at least 9-10 times a day using 70\% isopropyl alcohol sanitizer. The child rarely used soap and water despite being at home. Mother noticed inflamed dark colored skin of the dorsal aspect of the hands of the child, unaware of the cause. Despite the topical application of Desonide cream with a cosmetic moisturizing cream for 4-5 days, no improvement was seen.

The case history and examination of the hands of the child was discussed with dermatologist telephonically. The child was diagnosed with "isopropyl alcohol-based sanitizer-induced irritant contact dermatitis" due to frequent unsupervised use of sanitizer (Fig. 1).

The use of an offending sanitizer was immediately stopped. The child was instructed to use mild moisturizing soap, preferably (glycerine/cream-based), with plenty of water for sanitizing hands whenever required. A moisturizing cream massage was prescribed to be used 6-7 times, including application at night. Clobetasol, a topical corticosteroid cream, was prescribed to be

Correspondence to: Dr. Deep Inder, Professor and Head, Department of Pharmacology, Faculty of Dentistry, Jamia Millia Islamia, New Delhi, India. E-mail: drdeep73@gmail.com

(C) 2020 The Author(s). This open access article is distributed under a Creative Commons Attribution (CC-BY) 4.0 license. 
applied twice a day for 7-10 days. Tablet levocetirizine, 1 tablet once daily for 4-5 days, was prescribed to be taken at bedtime, based on the body weight to prevent itching.

The child was assessed based on the Naranjo causality assessment score which came out to be six that means a probable association of adverse effect with the use of $70 \%$ isopropyl alcohol. The child was reviewed after 1 week telephonically, along with the images of hands. Improvement was seen after 2 weeks of treatment (Fig. 2). Complete abolition of symptom/rash was seen after 3 weeks. No re-challenge was subjected to the child, and the patient was warned of the adverse effect of excessive/overuse of alcohol-based hand sanitizer.

\section{DISCUSSION}

Alcohol (70\%)-based sanitizer destroys outer lipid coating of Covid-19 virus by dissolving it, but at the cost of structural damage to proteins present in the outermost layer of the host skin, along with changes in intercellular lipids, leading to the inflammation and dryness of the skin [3]. Frequent handwashing with soap and detergents damages the normal skin flora, leading to colonization by harmful bacteria and viruses [4].

Both alcohol (70\%) and soaps/detergents have bactericidal and virucidal effects on the topical skin, but still, the majority of the studies claim that $70 \%$ alcohol is relatively better than the soaps, based on the safety, efficacy, and tolerability when applied on the skin with the same frequency [2,5-7] although some rare exceptions are there. An individual may be sensitive for one or

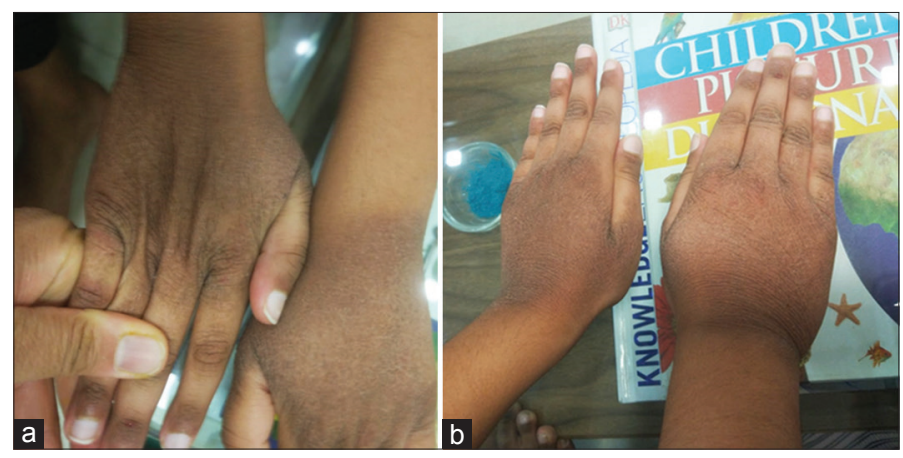

Figure 1: Isopropyl alcohol (70\%)-induced contact dermatitis by frequent repeated application for many days

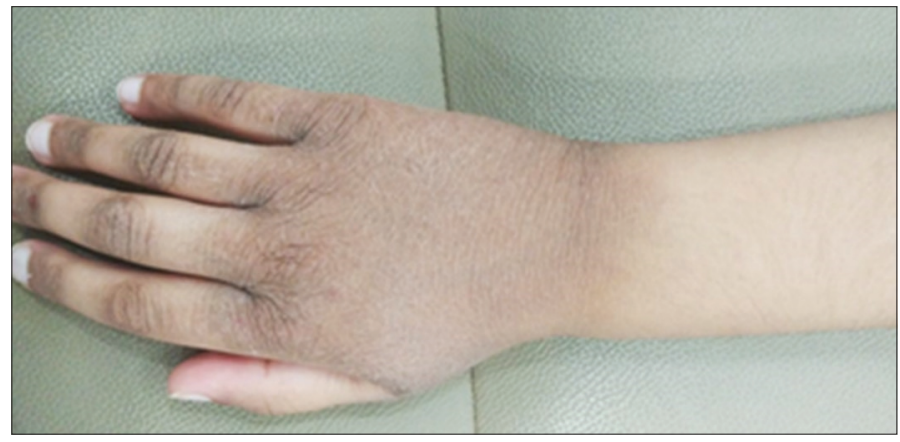

Figure 2: Remission of rash of contact dermatitis after subjecting to treatment more ingredients/chemicals present in hand hygiene products. Delayed types of hypersensitivity reactions are associated with frequent use of topical sanitizing products. In general, excipients in a formulation, which are otherwise pharmacologically inactive, are responsible for causing allergic reactions. These excipients may be in the form of stabilizing agents, binders, fragrance compounds, preservatives, emulsifying agents, benzyl, stearyl, isostearyl alcohol, propylene glycol, benzalkonium chloride, parabens, etc [8-11].

In the present case report, the child experienced itching, dryness, and redness of the skin of the hands due to the frequent use of $70 \%$ isopropyl alcohol-based hand sanitizer. As the use of alcohol-based hand sanitizer was stopped and topical corticosteroid, moisturizing (emollient) cream was applied on the skin of the hands for 2-3 weeks, a drastic improvement in the form of remission of allergic contact dermatitis rash was seen. Reporting the present case would create awareness among masses regarding the proper use of alcohol-based hand sanitizers with precautions.

\section{CONCLUSION}

Isopropyl alcohol (70\%)-based hand sanitizer should not be used indiscriminately. The use of such chemical sanitizers should be based on associated risk and benefit after following the manufacturer's instructions thoroughly. To prevent adverse reactions with the use of $70 \%$ isopropyl alcohol-based sanitizer, the use must be restricted while visiting outdoors. Mild soap and water followed by emollients should be used to maintain hand hygiene while staying indoors.

\section{ACKNOWLEDGMENT}

The authors are grateful to Vineet Kumar for his expert opinion regarding diagnosis in the present case.

\section{REFERENCES}

1. Lampel HP, Patel N, Boyse K, Brien SH, Zirwas MJ. Prevalence of hand dermatitis in inpatient nurses at a United States hospital. Dermatitis 2007; 18:140-2.

2. Bolon MK. Hand hygiene: An update. Infect Dis Clin 2016;30:591-607.

3. Guan WJ, Ni ZY, Hu Y, Liang W, Ou C, He J, et al. Clinical characteristics of coronavirus disease 2019 in China. N Engl J Med 2020;382:1708-20.

4. Girard R, Bousquet E, Carre E, Bert C, Coyault C, Coudrais S, et al. Tolerance and acceptability of 14 surgical and hygienic alcohol-based hand rubs. J Hosp Infect 2006;63:281-8.

5. Slotosch CM, Kampf G, Loffler H. Effects of disinfectants and detergents on skin irritation. Contact Dermatitis 2007;57:235-41.

6. Graham M, Nixon R, Burrell LJ, Bolger C, Johnson PD, Grayson ML. Low rates of cutaneous adverse reactions to alcohol-based hand hygiene solution during prolonged use in a large teaching hospital. Antimicrob Agents Chemother 2005;49:4404-5.

7. Wong VW, Cowling BJ, Aiello AE. Hand hygiene and risk of influenza virus infections in the community: A systematic review and meta-analysis. Epidemiol Infect 2014;142:922-32.

8. Pittet D, Allegranzi B, Sax H, Chraiti MN, Griffiths W, Richet H. Doubleblind, randomized, crossover trial of 3 hand rub formulations: Fast-track evaluation of tolerability and acceptability. Infect Control Hosp Epidemiol 2007;28:1344-51. 
9. Kownatzki E. Hand hygiene and skin health. J Hosp Infect 2003;55:239-45.

10. Rastogi SC, Heydorn S, Johansen JD, Basketter DA. Fragrance chemicals in domestic and occupational products. Contact Dermatitis 2001;45:221-5.

11. Cimiotti J, Marmur ES, Nesin M, Cook PH, Larson EL. Adverse reactions associated with an alcohol-based hand antiseptic among nurses in a neonatal intensive care unit. Am J Infect Control 2003;31:43-8.
Funding: None; Conflicts of Interest: None Stated.

How to cite this article: Inder D, Kumar P. Isopropyl alcohol (70\%)based hand sanitizer-induced contact dermatitis: A case report amid Covid-19. Indian J Case Reports. 2020;6(7):403-405. 